
\title{
25 Research Soure \\ Effects of Cruciate Embedding Fascia-Bone Flap Technique on Grade II - III Cerebral Spinal Fluid Leak in Endoscopic Endonasal Surgery
}

\section{WenJi Zhao}

The First Affiliated Hospital of Chongqing Medical University

\section{Gang Yang}

The First Affiliated Hospital of Chongqing Medical University

\section{RuiChun Li}

The First Affiliated Hospital of Xi'an JiaoTong University

\section{Gang Huo}

The First Affiliated Hospital of Chongqing Medical University

\section{Dong Gao}

The First Affiliated Hospital of Chongqing Medical University

\section{MingChuan Cao}

The First Affiliated Hospital of Chongqing Medical University

\section{XiaoShu Wang ( $\nabla$ xswang789@cqmu.edu.cn )}

The First Affiliated Hospital of Chongqing Medical University https://orcid.org/0000-0002-5648-9154

\section{Research article}

Keywords: Endoscopic endonasal surgery, CSF leak. Bone flap, Skull base reconstruction, Pedicle vascularized nasoseptal flap

Posted Date: May 7th, 2021

DOI: https://doi.org/10.21203/rs.3.rs-496704/v1

License: (c) (1) This work is licensed under a Creative Commons Attribution 4.0 International License. Read Full License 


\section{Abstract}

Background: Cerebral spinal fluid (CSF) leak remains an important issue in endoscopic endonasal surgery. A standard protocol of skull base closure has not been established yet, and application of rigid buttress has not been given sufficient attention. To emphasize the functions of support and fixation from rigid buttress in reconstruction, we introduce a technique of cruciate embedding fascia-bone flap (CEFB) using autologous bone graft to buttress fascia lata attaching to partially sutured skull base dural defect, and evaluate its efficacy in a consecutive case series of grade II-III CSF leak in EES.

METHODS: Data of consecutive patients with grade II-III CSF leak during EES were collected between May 2015 and May 2020. Skull base reconstructions were performed either with the CEFB, conventional PNSF, or combination of 2 methods. Related clinical data were compared and analyzed respectively.

RESULTS: There are 110, 65, and 23 patients included in CEFB, PNSF, and combination group respectively. CEFB demonstrated statistically similar effects on postoperative CSF leak (2.7\%) and intracranial infection (4.5\%) compared to PNSF $(3.1 \%, 3.1 \%)$, but with less morbidity of epistaxis (CEFB: 0\%, PNSF: $6.2 \%$ ) and nasal discomforts (CEFB: $0 \%$, PNSF: $7.7 \%$ ). The bed stay time (CEFB: $5.74 \mathrm{~d}$, PNSF: 8.83d) and hospitalization time (CEFB: 10.49d, PNSF: 13.58d) were shortened in CEFB group. Combination of CEFB and PNSF achieved 0 postoperative CSF leak in 23 highly susceptible patients with grade III leak and multiple high risk factors.

CONCLUSION: The CEFB technique is reliable and feasible to prevent postoperative CSF leak in EES. It can be used safely without PNSF in suitable cases, or applied in association with PNSF with high compatibility and security when necessary.

Trial RegistrationखCurrent Controlled Trials ChiCTR2100044764 (Chinese Clinical Trial Registry), as well as the date of registration $27^{\text {th }}$ March, 2020. Retrospectively registered.

\section{Background}

Endoscopic endonasal surgery (EES) has become popular to resect ventral skull base tumors with minimal invasiveness and good visibility [1-3]. But the risk of postoperative cerebral spinal fluid (CSF) leak remains an issue due to the challenging of watertight closure of skull base [4]. The incidence of CSF leak after EES has been reported to vary from 1.6 to $40 \%$ [5-12]. Meningitis, pneumocephalus, and other complications which may even lead to life threats, have great impact on the prognosis of patients $[5,13]$. Although variety of skull base reconstruction methods have emerged, a standard protocol has not yet been established. The introduction of pedicle vascularized nasoseptal flap (PNSF) has dramatically improved the outcome of skull base repair since 2006 [14]. It becomes a well-accepted or even dominant procedure on high flow CSF leak in EES. However, PNSF involves distinct anatomical transposition of nasal mucosa, and may cause complications of perforation, epistaxis, dysosmia, and nasal discomforts affecting quality of life [15-17]. It emphasizes the soft (membranous) reconstruction but lacks of rigid support on skull base. Methods represented by gasket-seal [6] and in-situ bone flap (ISBF) [18] have 
proposed rigid buttress in addition to soft reconstruction, and achieved satisfactory outcomes on preventing postoperative CSF leak. But artificial graft, PNSF, lumbar drainage (LD), and iodoform gauze nasal packing were still indispensable in these applications $[6,16,17,19]$.

We have been applying cruciate embedding fascia-bone flap (CEFB) technique in suitable cases of intraoperative grade II-III CSF leak since 2015, with the purpose of integrating soft repair, rigid buttress, and multilayer reconstruction. We aimed to restore the normal anatomical layers of skull base by using autologous material, and with less nasal interference. Another feature we targeted is that CEFB could be performed independently without routine PNSF, iodoform gauze and LD, although it can be totally PNSFcompatible when necessary. In this article, we describe this new skull base repair method in detail, and discuss its efficacy in a case series of consecutive patients.

\section{Materials And Methods}

\section{Patients and group}

Under approval of institutional ethic committee, we retrospectively collected data of consecutive patients who underwent EES by the same group of senior surgeons at our institution from May 2015 to May 2020. All patients were confirmed to have intraoperative grade II or III CSF leak corresponding to Esposito's Grade [20] (Fig.1a). Patients received CEFB alone were included as CEFB group; patients with unsuitable condition (insufficient bone graft harvest or oversize bone defect) for CEFB were treated with PNSF, and served as PNSF group; patients with grade III intraoperative CSF leak and high risk factors 3 for postoperative CSF leak (diabetes, age $>65$, hydrocephalus, body mass index (BMI) $>30$ [21], adoption of extended approach), received combination of CEFB and PNSF, and served as combination group.

Age, sex, BMI, diabetes, lesion volume, smoking, hypertension, surgical approach and pathology were recorded for statistical analysis to verify the consistency of baseline distribution between CEFB and PNSF groups. Combination group was not included in this baseline analysis for its apparent highly susceptible condition. We excluded recurrent tumor cases for their compromised tissue healing ability and local cicatrization would impair the reconstruction [22], then causing confounding fluctuation of data. Patients with accidental termination of treatment or loss of follow-up were also excluded.

\section{Surgical Technique}

Two-surgeon four-hand technique was used in all operations with high-definition endoscope (Karl Storz, Tuttlingen, Germany). Standard endoscopic endonasal approach (EEA) was mainly adopted in pituitary adenoma and Rathke cleft cyst, and extended EEA (EEEA) was mainly used in craniopharyngioma, meningioma, and invasive or giant pituitary adenoma. The multilayer closure strategy was applied in all groups.

\section{Inlay procedures}


The inlay part in all groups were identical. The absorbable accellular dermal matrix (ADM) (Heal-all, ZHBIO inc, Yantai, China) was used as the first subdural inlay. It was placed to cover the margin of residual diaphragma sellae (Fig.1b). In case of total loss of diaphragma sellae, the ADM was placed at the original diaphragma site, meticulously leaning on structures as optic chiasm, hypophyseal stalk, or tucking under internal carotid artery (ICA). Then, autologous fat graft harvested from patients' thigh was placed inside sellar space or corresponding subdural space under ADM to sustain the first layer (Fig.1c).

\section{Partial dural suturing}

The interrupted partial dural suturing was applied in all group. The suturing was made with 5-0 nylon by sliding-lock-knot technique as described before [8]. The dural incision was preferably made in " $\mathrm{H}$ ", " $\mathrm{T}$ ", " $\mathrm{Y}$ ", or inverted " $U$ " shape to facilitate the multi-point suturing of 3-5 stitches (Fig.1d).

\section{Onlay of fascia lata}

In CEFB and combination groups, the fasica lata onlay was according to protocols as below: fascia lata was tailored into rectangle shape, and placed over the dural defect either longitudally (sagittal direction) or transversely (coronary direction). We preferred the longitudal onlay in most cases for better convenience. Typically in extended EEA, the frontal edge of fascia lata reaches the planum sphenoidale, and the rear edge reaches upper clivus, extending at least $10 \mathrm{~mm}$ beyond the bone defect edges. Lateral edges of fascia should reach the lateral bone defect margin or slightly exceed within $2 \mathrm{~mm}$ (Fig.1e).

In PNSF group, the onlay of fascia lata was performed in conventional way of covering bone defect with redundancy of at least $10 \mathrm{~mm}$.

\section{Embedding of bone flap graft}

In CEFB and combination groups, bone flap graft was harvested from nasal septum, vomer, anterior wall of sphenoid sinus, or septum inside sphenoid sinus. The bone flap was countersunk and embedded under the edges of bone defect as a rigid buttress to press fascia lata on the dural defect. It is notable that the bone flap embedding was different from the circumferential wedging in gasket-seal. In CEFB procedure, it was wedged at 2 sides either longitudally or transversely, and placed vertically crossing upon the fascia lata, to finally form a cruciate embedding fascia-bone flap complex. The bone flap was trimmed and wedged with caution to avoid neurovascular injury. Typically, we transversly embedded (vertical to the longitudally placed fascia underneath) the bone flap under the lateral defect edges with an exceeding of 1-2.5mm (avoiding compression on optic nerve or ICA). Thus, the fascia could stretch out through the frontal and rear gaps between bone flap and defect edge, and be paved smoothly on skull base (Fig.1f).

In CEFB group, surplus fascia and fat graft were used to strengthen the whole constructs (Fig.1g). OutStretching fascia was fixed by Oxidized regenerated cellulose (Surgicel, EthiconInc, America) for apposition against bone surface. Absorbable lactide caprolactone co-polyesters (Nasopore, Polyganics, Groningen, The Netherlands) were filled in sphenoid sinus to sustain fascia (Fig.1h), and in nasal cavity 
to reposition mucosa back to septum. No glue, baloon or iodoform gauze was used in CEFB group (Fig.1i).

\section{PNSF application}

In PNSF and combination groups, a vascularized nasoseptal flap was harvested as described before [14] to cover the fascia abundantly as the last layer. Surplus fat graft and iodoform gauze was inserted into sphenoid sinus and nasal cavity to support the PNSF coverage.

\section{Postoperative management}

Supine position was mandatory in first postoperative $24 \mathrm{~h}$. Then, the head end of bed was gradually elevated $20-30^{\circ}$ per day unless CSF leak was detected. Patient was allowed to off bed after no CSF leak in persistent vertical sit posture for $4 \mathrm{~h}$. Lumbar drainage (LD) was not prophylactically used, but only performed when patient had sustained CSF leak or refractory intracranial infection. The nasal packing gauze was removed 10 days after surgery.

\section{Collection of intraoperative and postoperative data}

The volume of blood loss, surgery duration, resection degree, grade/size of CSF leak, intracranial infection, LD placement, LD duration, epistaxis, dysosmia, nasal discomforts, bed stay time and hospitalization time was recorded for comparison. Nasal discomforts was introduced as a subjective symptomological item evacuated 10 weeks after surgery, including sense of dryness, pain, nasal obstruction, runny nose and nasal odor.

\section{Statistical analysis}

Comparisons of categorical variables were analyzed by Chi-squared test or Fisher's exact test. Student $t$ test was used for continuous variables with normal distribution, and Rank-sum test was employed for variables of non-normal distribution. The multiple-test correction was applied using the Bonferroni method. SPSS 25.0 was used for all analyses. Differences with Pख0.05 were considered statistically significant.

\section{Results}

\section{Baseline Characteristics}

In this study, Of 201 patients who had intraoperative CSF leak of grade II and III, 3 cases were excluded for losing follow-up. All included patients were followed-up for at least 6 months. There were 110 patients underwent CEFB alone for reconstruction, and 65 patients underwent PNSF for their unsuitable condition for CEFB. There were no significant differences in the preoperative baseline between 2 groups (Table 1). 
Combination group consisted of 23 patients of grade III intraoperative CSF leak with at least 3 high risk factors. This group had more susceptible baseline condition for postoperative CSF leak than other 2 groups. Data from combination group was included in the subdivided comparison of grade III leak and hydrocephalus for reference.

\section{Intraoperative And Postoperative Condition}

The grade/size of intraoperative CSF leak in 2 groups showed no significant difference. The incidence of postoperative CSF leak in CEFB group (2.7\%) was slightly lower than PNSF group (3.1\%), but without statistical significance. Intracranial infection and LD placement in CEFB group showed no statistical difference with PNSF group. The significant reduction of LD duration, bed stay time, and hospitalization time in CEFB group were demonstrated compared with PNSF group. CEFB was also associated with significantly less occurrence of epistaxis and nasal discomfort. The surgery duration of the CEFB was longer than PNSF, which was related to the meticulous trimming and embedding of bone flap graft. All comparisons above were listed in detail in Table 2.

During the process of bone flap embedding, small amount of epidural hemorrhages often occurred, but could be easily controlled by gelatin sponge. No CEFB-related neurovascular injury happened. One case in CEFB group and another in PNSF group suffered from sustained postoperative CSF leak were cured by reoperation. The one in CEFB group was caused by local curling of the fascia lata due to the excessive compression of bone flap. Another in PNSF group was owing to the loosening of the PNSF. Other cases of postoperative CSF leak were healed by LD placement and postural confinement.

No fracture, dislocation, or detachment of CEFB construct was observed in scheduled debridement under endoscope 3 weeks after surgery (Fig. 2a). Bone flap and fascia was found to be in place and firmly attaching to defect. Osteal structure reconstruction was assessed by pre- and postoperative CT scan (Fig. 2b, 2c, 2d and 2e). The long term stability of CEFB was examined by CT scan 3-6 months after surgery (Fig. 2f, 2g).

\section{Subdivided Comparisons}

Data of subdivided characteristics are summarized in Table 3. In grade II leak comparison, no statistical difference exists between CEFB and PNSF group on postoperative CSF leak, infection, or LD placement. In grade III leak comparison, outcomes were presented with no statistical differences among groups. Of 23 patients with multiple risk factors in combination group, none postoperative leak occurred.

In cases with preoperative hydrocephalus, CEFB and combination groups yielded an outcome of 0 postoperative CSF leak in 15 cases, although the statistical significance was not achieved due to small sample. 


\section{Discussion}

An ideal skull base reconstruction by our cognition should implement philosophies including: 1 . Separating intracranial space from aerodigestive tract. 2. Promoting rapid and stable adhesion, cicatrization, and epithelialization at defect site. 3. Restoring the original anatomical layers of bone and dura. 4. Excellence in feasibility, safety, and patients' subjective experience $[4,6,23,24]$. According to these points, we have launched CEFB application since 2015. It may be unusual that our study included substantial pituitary adenoma cases because adenoma of epidural origin usually has low rate of intraoperative CSF leak [6]. However, as a senior adenoma center covering 30 million population, our institution admitted high proportion of giant or invasive adenoma. Due to the compromised or breached diaphragm sellae in these patients, the morbidity and severity of intraoperative CSF leak are higher than general level. Percentage of grade III leak featured by huge diaphragma defect and direct opening to suprasellar cisterns is $48.5 \%$ in all included cases. The baseline data distribution in groups of CEFB and PNSF had statistically confirmed consistency, which provided solid comparability for two methods.

\section{The purposes of inlay in CEFB}

Multilayer reconstruction has become a commonly accepted principle in EES [14, 25-28]. The inlay materials are not adequate for CSF blockage, but they contribute to reducing leak size and CSF flow, eliminating dead space, buffering impact of CSF pulsation, and alleviating CSF pooling or soaking [29, 30]. The key point of CEFB inlay procedure is that the volume of fat graft should be finely adjusted to obtain optimal subdural tension fitting the buttress pressure of wedged bone graft, generating appropriate tightness of attaching between fascia and dura. Either excessive or inadequate pressure would hinder the reconstruction stability, which is illustrated by the reoperation of one failure case in CEFB group described above.

\section{The benefits of partial dural suturing in CEFB}

With the advances of surgical technology, the deep suturing and knotting are no longer big issues in EES, but the literally "watertight" suturing is still technically challenging due to the dural dehydration, fragility, or electrocauterization $[8,31]$. The partial suturing was not enough to seal CSF leak, but we deem it still has benefits as: 1. Reducing the dural defect and confining it under the center of rigid buttress. 2 . Providing dural interface for onlay fascia to attach, avoiding direct contact between fascia and inlay

grafts. 3. Anchoring ADM and fat in place and avoiding them fall into suprasellar cistern or ventricle [6]. 4. Increasing intrasellar tension and compactness [32].

\section{Comparison between CEFB and gasket-seal}

CEFB shares the same concept of rigid reconstruction with other methods represented by gasket-seal [6] and ISBF [18]. CEFB has the similarity of "hard material buttressing soft structure" with those two techniques, but with significant modifications. As its name addressed, gasket-seal focuses on the watertight closure of defect. The circumferentially wedged material works as a plug wrapped by fascia to 
increase sealability, so its shape are required to be highly matched to the shape of bone defect $[6,33]$. Artificial material is frequently used $[6,19,34]$, because the autologous bone graft does not always perfectly fit the defect. The core of CEFB is the buttress pressure firmly holding fascia lata on the dura to promote tight attaching and mutual adhesion. Firstly, bone flap in CEFB was embedded at only two sides of bone defect, instead of fully circumferential wedging. The size of bone flap is qualified by adequate length on only one axis. This is an easier requirement for bone graft harvest, which promotes the usage of autologous bone in more cases, and brings lower costs and risks of infection or rejection. In our study, $67.2 \%(133 / 198)$ of all cases have acquired satisfactory autologous bone harvest. Secondly, the two-side embedding of CEFB allows fascia lata to stretch out through the gaps on non-wedging sides and to be paved smoothly on skull base. But in gasket-seal, the fascia lata formed "cauliflower leaf" shape $[6,33]$ due to the tight depression in the center [6]. The tilted or curled edge of fascia is hard to be flattened to provide smooth attaching. Thirdly, the partial dural suturing ensures the correct epidural embedding of bone flap, avoiding it being accidentally misplaced into subdural space. The firm contacting between sutured dura and fascia also assists the adhesion formation. Finally, the gasket-seal is not ideal in case of defect traverses two geometric planes, because the rigid buttress is not curved to fit the contour of defect [6]. In our EEEA cases with sufficient bone graft harvest, we used two separated bone flaps to wedge at different defect planes respectively (Fig. 3a). The fascia lata then could be supported evenly and hold in place on angled planes.

\section{Comparison between CEFB and ISBF}

ISBF is another typical method of rigid buttress reconstruction. Its advantages are eminent in perfect contour match and tissue compatibility [18]. The forming of ISBF is by microdrill of $2.5 \mathrm{~mm}$ diameter diamond burr, which inevitably inflicts loss of bone substance. Although it can be adjusted to get several wedging points, the stability of this fixation is limited. Besides, ISBF is tend to be "placed" on the defect plane, rather than countersunk below it. The buttressing pressure applied by ISBF is weaker compared to the firm wedging in CEFB. Moreover, the fundamental requirement of ISBF is the intact of skull base bone structure without tumor invasion. This indication may be easy to meet in cases of suprasellar tumor, but high proportion of pituitary adenoma in our case series often involved infiltration or sabotage of bone.

\section{Resistance of CEFB against counteracting forces}

The forces of brain gravity, CSF pulsation, and intracranial pressure are great concerns in skull base repair. These downward forces are prone to incur compromise of reconstruction [32]. Hence, iodoform gauze packing, lumbar drainage, and intranasal balloon et al are used as countermeasures [6, 34, 35]. The integrity of CEFB is sturdy enough to resist these forces due to the rigidity of firmly wedged bone flap. No dislocation or fracture of bone flap was observed in all of our CEFB cases, even without iodoform gauze packing or lumbar drainage. These downward forces might be conjecturally helpful to form more solid compression of CEFB structure, to strengthen the watertight and attaching. This mechanism possibly contributed to the shortened bed stay time in CEFB group. Especially in cases with preoperative 
hydrocephalus, either CEFB alone or combination with PNSF exhibited good outcome of 0 postoperative CSF leak in 15 cases.

\section{Considerations about PNSF application}

PNSF is a milestone in development of skull base reconstruction for its fast healing and long-term security of closure [14]. But the harvest of PNSF necessitates long incision on nasal septum to mobilize extensive piece of mucosa, and migrate it to skull base. The exposed donor site needs 6-12 weeks to be re-epithelialized [27]. Nasal complications related to this extensive shift of mucosa are not rare [15-17, 36]. The nasal packing of iodoform gauze or balloon regularly used in associate with PNSF also influences mucosa regeneration and patients' subjective experience due to the intranasal pressure and stimulation [15]. Garcia-Navarro et al reported PNSF did not make statistical difference in their gasketseal practition, which raised the question on PNSF necessity [6]. In our study, it also showed no significant difference in postoperative CSF leak and infection between CEFB and PNSF, and nasal complications are significantly reduced in CEFB group. The effectiveness of CEFB is comparable and proximate with other representative reports on postoperative CSF leak (Table 4). Our data suggests that in presence of appropriate CEFB with multilayer reconstruction, PNSF may not be a sole mandatory option. Pros-cons of PNSF should be individually weighed, and any form of PNSF "abuse" is not justified. We do not attempt to simply replace PNSF with CEFB. On the contrary, CEFB is not exclusive but highly compatible with PNSF. In 23 cases of grade III CSF leak with multiple risk factors, the combination of 2 techniques achieved 0 postoperative CSF leak. It implied that with the additional protection from PNSF, CEFB could provide reliable security in high risk cases.

\section{Limitations of CEFB and present study}

First, harvest of bone flap is not always sufficient or available due to anatomical variations or tumor invasion, especially in case of oversize defect extending laterally. Second, the coverage of fascia under the wedging edges of defect is limited. Several measures could be taken to improve the limitations: 1. During surgical approach, any bone structures with utilizing potential should be preserved by avoiding excessive grinding of microdrill. 2. Bone graft could be tailored into narrow strips to intervally wedge at defect (Fig.3b). 3. The wedging sides of defect could be carefully enlarged to expose more dural surface for fascia attaching (on premise of guaranteeing embedding stability). 4. Dural defect could be minimized by improving dural incision design and suturing. Finally, in the worst scenario, when all measures turn out to be unassuring, PNSF remains the trustworthy resort.

The number of cases in our study is still limited, and the establishment of randomized control is difficult. Current follow-up period of 6 months is also not enough to perform long-term evaluation. More rigorous study design and accumulation of cases are required for further assess of CEFB technique.

\section{Conclusion}


CEFB is an effective and reliable reconstruction method to prevent postoperative CSF leak in EES, by secured rigid buttress integrated with multilayers soft tissue repair. In most cases of grade II and considerable part of grade III intraoperative CSF leaks, the independent using of CEFB has similar effect with conventional PNSF on postoperative CSF leak, and with less nasal complications, shorter bed stay time and better patients' subjective experience. For grade III leak cases with multiple high risk factors or oversize defect, CEFB can be highly feasibly combined with PNSF to secure reconstruction outcomes.

\section{Abbreviations}

CEFB: cruciate embedding fascia-bone flap; PNSF: pedicle vascularized nasoseptal flap; CSF: cerebral spinal fluid; EES: endoscopic endonasal surgery; ISBF: in-situ bone flap; LD: lumbar drainage; BMI: body mass index; EEA: endoscopic endonasal approach $\triangle E E E A$ : extended endoscopic endonasal approach; ADM: accellular dermal matrix; ICA: internal carotid artery; CT: computed tomography; ACA: anterior cerebral artery; OC: optic chiasm; BF: bone flap; FL: fascia lata; DS: diaphragma sellae; PS: pituitary stalk; SC: Surgicel; NP: Nasopore; M: mucosa; SE: septum.

\section{Declarations}

\section{Acknowledgments}

Not Applicable.

\section{Funding}

The authors declared that this study has received no financial support.

\section{Availability of data and materials}

The datasets of the current study are available from the corresponding author on reasonable request and from the Neurosurgery of the First Affiliated Hospital of Chongqing Medical University.

\section{Authors' contributions}

ZWJ: Data acquisition and statistical analysis, also drafting the manuscript; YG: The inclusion and exclusion of research objects, also participated in data analysis. LRC: Data acquisition and analysis. HG: Designing the research. GD: Data acquisition and assisted statistical analysis. CMC: Data analysis. WXS: Data analysis and revision of manuscript, also designed the concept of the study. All authors have approved the manuscript.

\section{Competing interests}

The authors declare that they have no conflict of interest.

\section{Ethical approval}


All procedures performed in studies were in accordance with the ethical standards of Institutional Review Board of the First Affiliated Hospital of Chongqing Medical University and with the 1964 Helsinki Declaration and its later amendments.

\section{Informed consent}

Written informed consent was obtained from all participants.

\section{CONSORT guidelines}

Our study adheres to CONSORT guidelines and include a completed CONSORT checklist as an additional file with the manuscript.

\section{Author details}

[1]Department of Neurosurgery, the First Affiliated Hospital of Chongqing Medical University, 1 \# Youyi Road, Yuzhong District, Chongqing 400016, People's Republic of China. 2Department of Neurosurgery, the First Affiliated Hospital of Xi'an Jiaotong University, 277 West Yanta Road, Xi'an 710061, People's Republic of China

\section{References}

1. Park HR, Kshettry VR, Farrell CJ, Lee JM, Kim YH, Won TB, Han DH, Do H, Nyguist G, Rosen M, Kim DG, Evans JJ, Paek SH. Clinical Outcome After Extended Endoscopic Endonasal Resection of Craniopharyngiomas. Two-Institution Experience World Neurosurg. 2017;103:465-74. doi:10.1016/j.wneu.2017.04.047.

2. Bander ED, Singh H, Ogilvie CB, Cusic RC, Pisapia DJ, Tsiouris AJ, Anand VK, Schwartz TH. Endoscopic endonasal versus transcranial approach to tuberculum sellae and planum sphenoidale meningiomas in a similar cohort of patients. J Neurosurg. 2018;128(1):40-8. doi:10.3171/2016.9.Jns16823.

3. Cavallo LM, de Divitiis O, Aydin S, Messina A, Esposito F, laconetta G, Talat K, Cappabianca P, Tschabitscher M. Extended endoscopic endonasal transsphenoidal approach to the suprasellar area: anatomic considerations-part 1. Neurosurgery. 2008;62(6 Suppl 3):1202-12. doi:10.1227/01.neu.0000333786.98596.33.

4. Cavallo LM, Messina A, Esposito F, de Divitiis O, Dal Fabbro M, de Divitiis E, Cappabianca P. Skull base reconstruction in the extended endoscopic transsphenoidal approach for suprasellar lesions. $J$ Neurosurg. 2007;107(4):713-20. doi:10.3171/jns-07/10/0713.

5. Elshazly K, Kshettry VR, Farrell CJ, Nyquist G, Rosen M, Evans JJ, Clinical Outcomes After Endoscopic Endonasal Resection of Giant Pituitary Adenomas. World Neurosurg, (2018). 114: p. e447-e456. doi:10.1016/j.wneu.2018.03.006. 
6. Garcia-Navarro V, Anand VK, Schwartz TH. Gasket seal closure for extended endonasal endoscopic skull base surgery: efficacy in a large case series. World Neurosurg, (2013). 80(5): p. 563-8. doi:10.1016/j.wneu.2011.08.034.

7. Gardner PA, Kassam AB, Thomas A, Snyderman CH, Carrau RL, Mintz AH, Prevedello DM. Endoscopic endonasal resection of anterior cranial base meningiomas. Neurosurgery. 2008;63(1):36-52. doi:10.1227/01.Neu.0000335069.30319.1e. discussion 52 - 4.

8. Hara T, Akutsu H, Yamamoto T, Tanaka S, Takano S, Ishikawa E, Matsuda M, Matsumura A, Cranial Base Repair Using Suturing Technique Combined with a Mucosal Flap for Cerebrospinal Fluid Leakage During Endoscopic Endonasal Surgery. World Neurosurg, (2015). 84(6): p. 1887-93. doi:10.1016/j.wneu.2015.08.025.

9. Ishikawa T, Takeuchi K, Nagata Y, Choo J, Kawabata T, Ishizaki T, Wakabayashi T. Three types of dural suturing for closure of CSF leak after endoscopic transsphenoidal surgery. J Neurosurg, (2018). p. 1-7.

10. Juraschka K, Khan OH, Godoy BL, Monsalves E, Kilian A, Krischek B, Ghare A, Vescan A, Gentili F, Zadeh $\mathrm{G}$. Endoscopic endonasal transsphenoidal approach to large and giant pituitary adenomas: institutional experience and predictors of extent of resection. J Neurosurg. 2014;121(1):75-83. doi:10.3171/2014.3.Jns131679.

11. Koutourousiou M, Fernandez-Miranda JC, Stefko ST, Wang EW, Snyderman CH, Gardner PA. Endoscopic endonasal surgery for suprasellar meningiomas: experience with 75 patients. $J$ Neurosurg. 2014;120(6):1326-39. doi:10.3171/2014.2.Jns13767.

12. Marigil Sanchez M, Karekezi C, Almeida JP, Kalyvas A, Castro V, Velasquez C, Gentili F. Management of Giant Pituitary Adenomas: Role and Outcome of the Endoscopic Endonasal Surgical Approach. Neurosurg Clin N Am. 2019;30(4):433-44. doi:10.1016/j.nec.2019.05.004.

13. Komotar RJ, Starke RM, Raper DM, Anand VK, Schwartz TH. Endoscopic endonasal compared with microscopic transsphenoidal and open transcranial resection of giant pituitary adenomas. Pituitary. 2012;15(2):150-9. doi:10.1007/s11102-011-0359-3.

14. Hadad G, Bassagasteguy L, Carrau RL, Mataza JC, Kassam A, Snyderman CH, Mintz A. A novel reconstructive technique after endoscopic expanded endonasal approaches: vascular pedicle nasoseptal flap. Laryngoscope. 2006;116(10):1882-6. doi:10.1097/01.mlg.0000234933.37779.e4.

15. Lavigne P, Faden DL, Wang EW, Snyderman CH. Complications of Nasoseptal Flap Reconstruction: A Systematic Review. J Neurol Surg B Skull Base. 2018;79(Suppl 4):S291-s299. doi:10.1055/s-00381668158.

16. Alobid I, Enseñat J, Mariño-Sánchez F, Rioja E, de Notaris M, Mullol J, Bernal-Sprekelsen M. Expanded endonasal approach using vascularized septal flap reconstruction for skull base tumors has a negative impact on sinonasal symptoms and quality of life. Am J Rhinol Allergy. 2013;27(5):426-31. doi:10.2500/ajra.2013.27.3932.

17. Tam S, Duggal N, Rotenberg BW. Olfactory outcomes following endoscopic pituitary surgery with or without septal flap reconstruction: a randomized controlled trial. Int Forum Allergy Rhinol. 
2013;3(1):62-5. doi:10.1002/alr.21069.

18. Jin B, Wang XS, Huo G, Mou JM, Yang G. Reconstruction of skull base bone defects using an in situ bone flap after endoscopic endonasal transplanum-transtuberculum approaches. Eur Arch Otorhinolaryngol. 2020;277(7):2071-80. doi:10.1007/s00405-020-05911-1.

19. Conger A, Zhao F, Wang X, Eisenberg A, Griffiths C, Esposito F, Carrau RL, Barkhoudarian G, Kelly DF. Evolution of the graded repair of CSF leaks and skull base defects in endonasal endoscopic tumor surgery: trends in repair failure and meningitis rates in 509 patients. J Neurosurg. 2018;130(3):86175. doi:10.3171/2017.11.Jns172141.

20. Esposito F, Dusick JR, Fatemi N, Kelly DF, Graded repair of cranial base defects and cerebrospinal fluid leaks in transsphenoidal surgery. Oper Neurosurg (Hagerstown), (2007). 60(4 Suppl 2): p. 295303; discussion 303-4. doi:10.1227/01.Neu.0000255354.64077.66.

21. Sun I, Lim JX, Goh CP, Low SW, Kirollos RW, Tan CS, Lwin S, Yeo TT. Body mass index and the risk of postoperative cerebrospinal fluid leak following transsphenoidal surgery in an Asian population. Singapore Med J. 2018;59(5):257-63. doi:10.11622/smedj.2016159.

22. Lee JY, Barroeta JE, Newman JG, Chiu AG, Venneti S, Grady MS. Endoscopic endonasal resection of anterior skull base meningiomas and mucosa: implications for resection, reconstruction, and recurrence. J Neurol Surg A Cent Eur Neurosurg. 2013;74(1):12-7.

23. Gil Z, Abergel A, Leider-Trejo L, Khafif A, Margalit N, Amir A, Gur E, Fliss DM. A comprehensive algorithm for anterior skull base reconstruction after oncological resections. Skull Base. 2007;17(1):25-37. doi:10.1055/s-2006-959333.

24. Laufer I, Anand VK, Schwartz TH. Endoscopic, endonasal extended transsphenoidal, transplanum transtuberculum approach for resection of suprasellar lesions. J Neurosurg. 2007;106(3):400-6. doi:10.3171/jns.2007.106.3.400.

25. Clavenna MJ, Turner JH, Chandra RK. Pedicled flaps in endoscopic skull base reconstruction: review of current techniques. Curr Opin Otolaryngol Head Neck Surg. 2015;23(1):71-7. doi:10.1097/moo.0000000000000115.

26. Eloy JA, Kuperan AB, Choudhry OJ, Harirchian S, Liu JK. Efficacy of the pedicled nasoseptal flap without cerebrospinal fluid (CSF) diversion for repair of skull base defects: incidence of postoperative CSF leaks. Int Forum Allergy Rhinol. 2012;2(5):397-401. doi:10.1002/alr.21040.

27. Kassam AB, Prevedello DM, Carrau RL, Snyderman CH, Thomas A, Gardner P, Zanation A, Duz B, Stefko ST, Byers K, Horowitz MB. Endoscopic endonasal skull base surgery: analysis of complications in the authors' initial 800 patients. J Neurosurg. 2011;114(6):1544-68. doi:10.3171/2010.10.Jns09406.

28. Zanation AM, Carrau RL, Snyderman CH, McKinney KA, Wheless SA, Bhatki AM, Gardner PA, Prevedello DM, Kassam AB. Nasoseptal flap takedown and reuse in revision endoscopic skull base reconstruction. Laryngoscope. 2011;121(1):42-6. doi:10.1002/lary.21162.

29. Oakley GM, Christensen JM, Winder M, Jonker BP, Davidson A, Steel T, Teo C, Harvey RJ. Collagen matrix as an inlay in endoscopic skull base reconstruction. J Laryngol Otol. 2018;132(3):214-23. 
doi:10.1017/s0022215117001499.

30. Prickett KK, Wise SK. Grafting materials in skull base reconstruction. Adv Otorhinolaryngol. 2013;74:24-32. doi:10.1159/000342265.

31. Nishioka H, Izawa H, Ikeda Y, Namatame H, Fukami S, Haraoka J. Dural suturing for repair of cerebrospinal fluid leak in transnasal transsphenoidal surgery. Acta Neurochir (Wien). 2009;151(11):1427-30. doi:10.1007/s00701-009-0406-2.

32. Heng L, Zhang S, Qu Y. Cross-reinforcing suturing and intranasal knotting for dural defect reconstruction during endoscopic endonasal skull base surgery. Acta Neurochir (Wien). 2020;162(10):2409-12. doi:10.1007/s00701-020-04367-w.

33. Singh H, Essayed WI, Schwartz TH. Endoscopic technology and repair techniques. Handb Clin Neurol. 2020;170:217-25. doi:10.1016/b978-0-12-822198-3.00042-2.

34. Zhao D, Tao S, Zhang D, Qin M, Bao Y, Wu A. "Five-layer gasket seal" watertight closure for reconstruction of the skull base in complex bilateral traumatic intraorbital meningoencephaloceles: a case report and literature review. Brain Inj. 2018;32(6):804-7. doi:10.1080/02699052.2018.1440631.

35. Hu F, Gu Y, Zhang X, Xie T, Yu Y, Sun C, Li W, Combined use of a gasket seal closure and a vascularized pedicle nasoseptal flap multilayered reconstruction technique for high-flow cerebrospinal fluid leaks after endonasal endoscopic skull base surgery. World Neurosurg, (2015). 83(2): p. 181-7. doi:10.1016/j.wneu.2014.06.004.

36. Thorp BD, Sreenath SB, Ebert CS, Zanation AM. Endoscopic skull base reconstruction: a review and clinical case series of 152 vascularized flaps used for surgical skull base defects in the setting of intraoperative cerebrospinal fluid leak. Neurosurg Focus. 2014;37(4):E4. doi:10.3171/2014.7.Focus14350.

\section{Tables}

Due to technical limitations, table 1 to 4 is only available as a download in the Supplemental Files section.

\section{Figures}




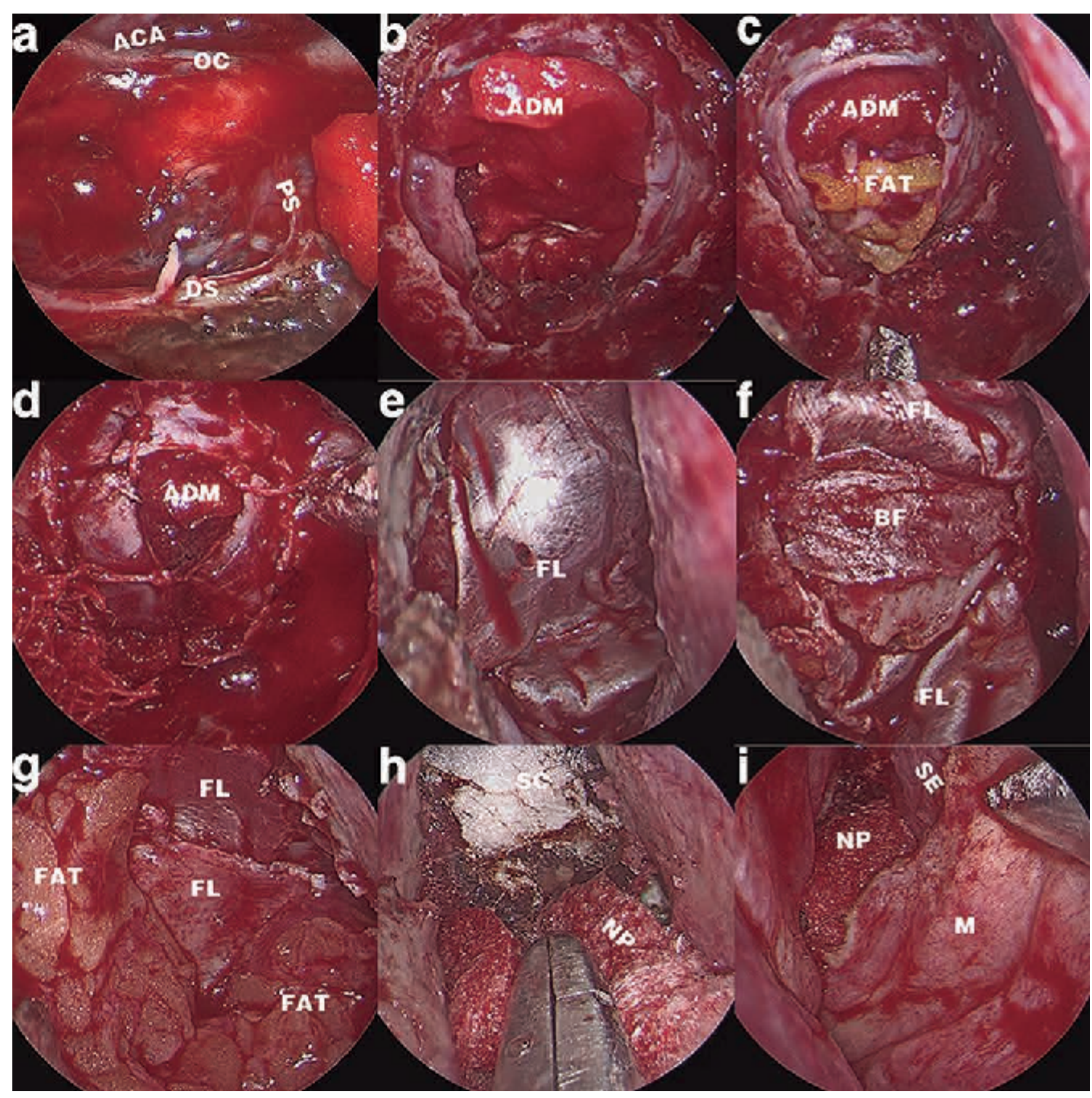

\section{Figure 1}

Representative intraoperative images of CEFB procedures. a. After removal of a giant pituitary adenoma breaching diaphragma, grade $\otimes C S F$ leak was presented. $b$. The absorbable ADM was placed to cover the margin of residual diaphragma as the first subdural inlay. c. Optimal amount of autologous fat graft was placed inside sellar space to sustain ADM and generate appropriate tension to fit the following steps of rigid buttress. $d$. Partial dural suturing of 3 stitches was applied on the " $Y$ " shape dural incision to reduce the dural defect and confine it under the center of rigid buttress. e. Onlay of fascia lata was longitudally placed to cover dural defect with redundancy of $10 \mathrm{~mm}$ on the front and rear end. Lateral edges of fascia slightly exceeded the lateral bone defect margin. f. Bone flap graft was transversly embedded under the lateral defect edges to buttress the longitudally placed fascia underneath, forming a cruciate embedding 
complex. The fascia could stretch out through the frontal and rear gaps between bone flap and defect edge g. Surplus grafts of fascia and fat were used to cover and strengthen whole CEFB constructs. $\mathrm{h}$. Surgicel and Nasopore were filled inside sphenoid sinus to fix and support fat and fascia. i. Nasal mucosa was repositioned back to the septum without harvesting of PNSF. ACA =anterior cerebral artery, $A D M=$ acellular dermis matrix,$O C=$ optic chiasm, $B F=$ bone flap, $F L=$ fascia lata, $D S=$ diaphragma sellae, $\mathrm{PS}=$ pituitary stalk, $\mathrm{SC}=$ Surgicel, $\mathrm{NP}=$ Nasopore, $\mathrm{M}=$ mucosa, $\mathrm{SE}=$ septum

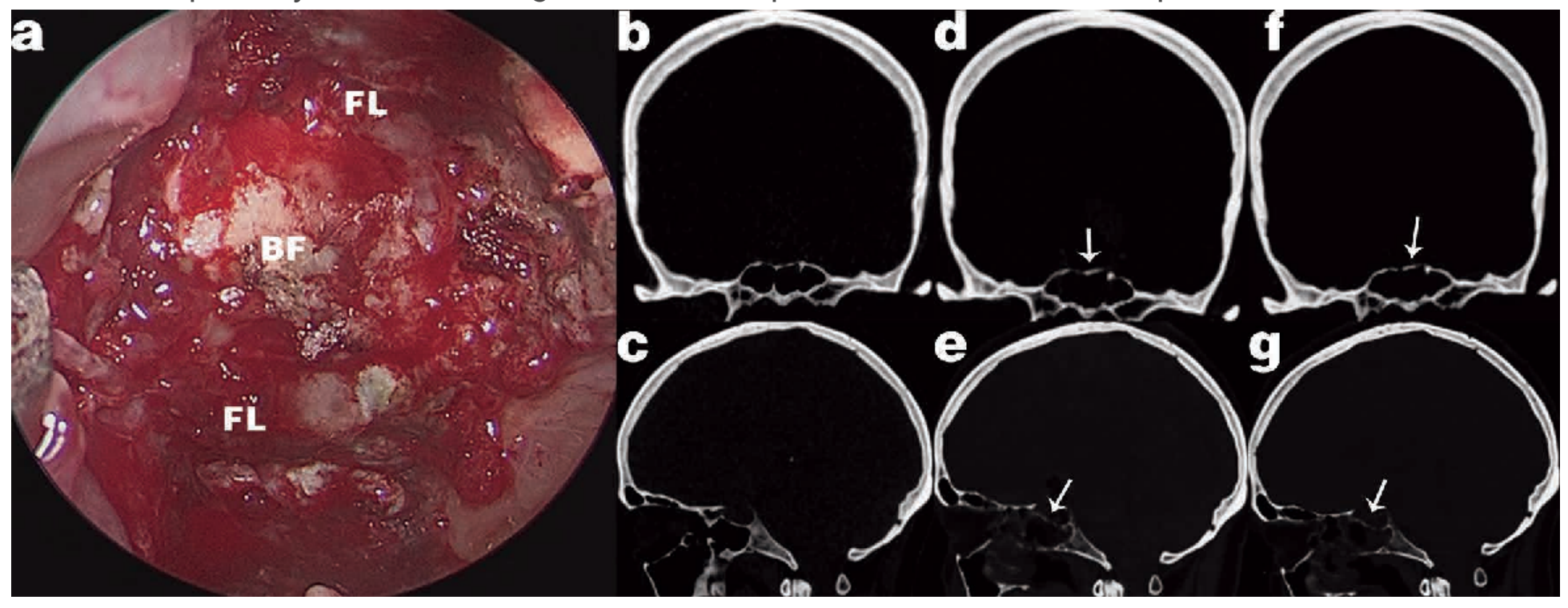

\section{Figure 2}

Representative postoperative images of CEFB outcomes. a. In debridement under endoscope 3 weeks after surgery, bone flap and fascia was found to be in place and firmly attaching to defect. b. Preoperative coronal CT image of skull base bone structure. c. and sagittal. $\mathrm{d}$. Immediate postoperative coronal CT image of CEFB reconstruction. e. and sagittal. f. 3 months after surgery, coronal CT image demonstrated no dislocation or detachment of bone flap. g. and saggital. $\mathrm{BF}=$ bone flap, $\mathrm{FL}=$ fascia lata, Arrowhead $=$ bone flap graft 


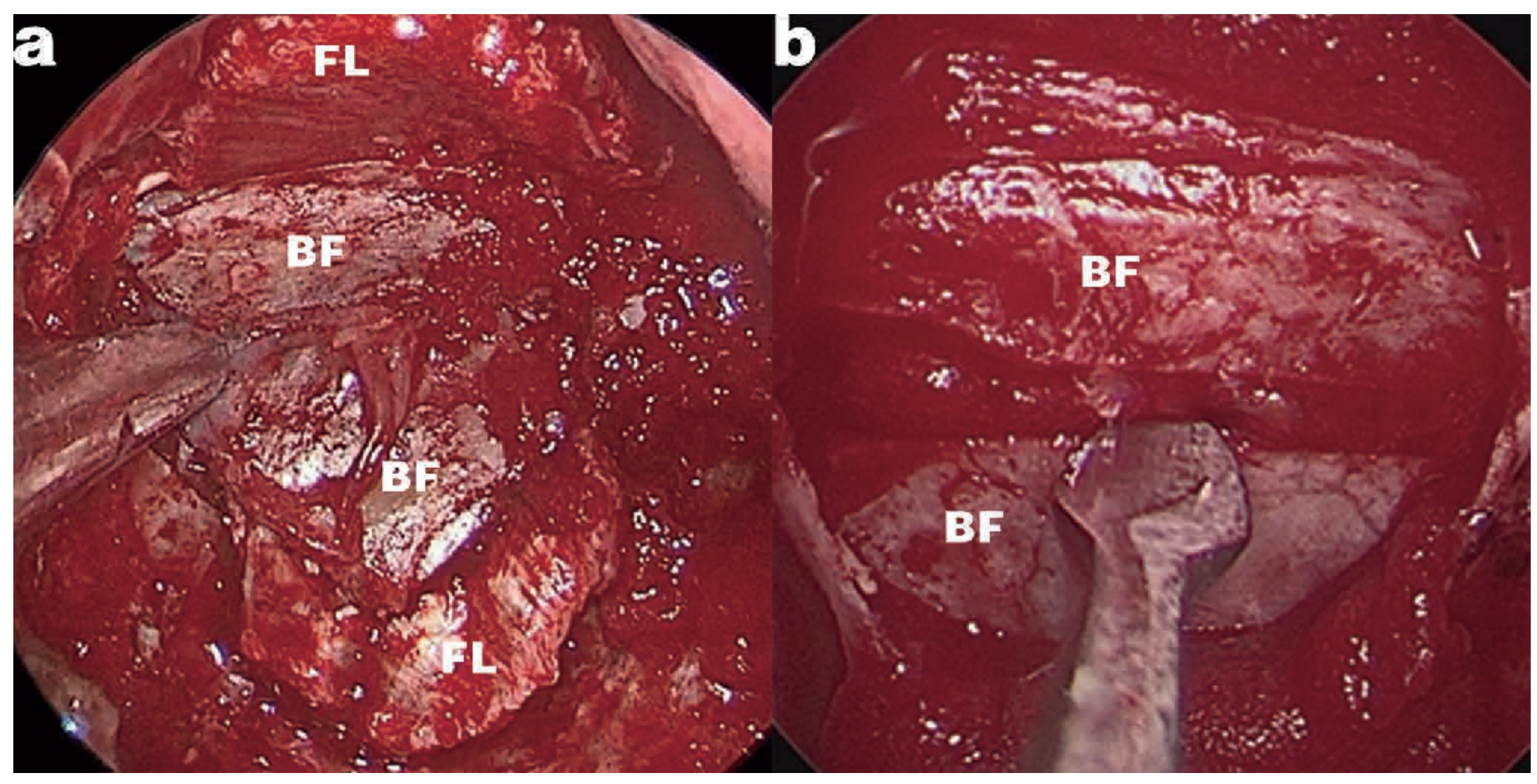

\section{Figure 3}

Representative intraoperative images of CEFB variants. a. Two separated bone flap grafts was embedded at planum sphenoidale and sellar floor respectively, buttressing fascia to different directions on angled planes. b. Bone graft was tailored into narrow strips to intervally wedge at defect for economical using of limited bone graft harvest. $\mathrm{BF}=$ bone flap, $\mathrm{FL}=$ fascia lata

\section{Supplementary Files}

This is a list of supplementary files associated with this preprint. Click to download.

- Table1Comparisonofbaselinecharacteristics.xIsx

- Table2Intraoperativeandpostoperativecharacteristics.xlsx

- Table3Subdividedcharacteristicscomparisons.xlsx

- Table4Literaturesreviewofskullbaserepair.xlsx

- CONSORTChecklist.doc 